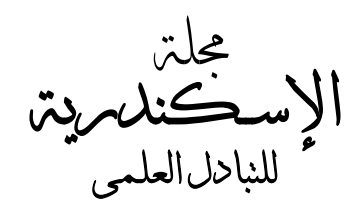

\begin{tabular}{|c|c|c|}
\hline$r \cdots \wedge$ & أكتو بر - ديسمبر & بحلد و r \\
\hline
\end{tabular}

الآثار التعليمية لبرنامج تدريب إرشادي في ججال تدريب المدربين لأعضاء جمعيات تنمية

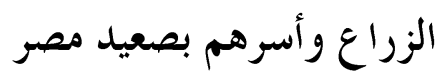

هدى محمد ماهر '

بشأها قبل التدريب، وذلك فف مقابل ب بنود مهارية فقط بنسبة

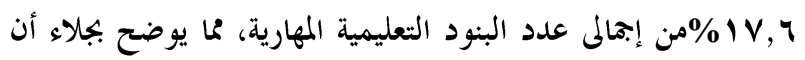

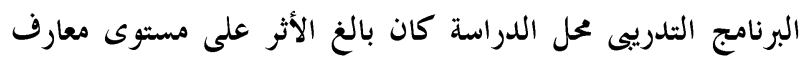
المثدربين فى مجال تدريب المدربين.

المقدمسـة والمشكلة البحثية

تتطلب التنمية موردا بشريا يستطيع أن يستوعب عناصرها

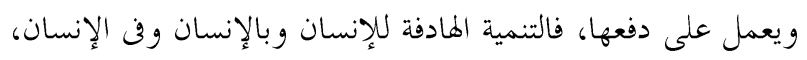
حيث تعرف التنمية البشرية كأحد مناهج تنمية البختمعات المحلية على أها "توسيع خيارات الناس وتعزيز قدراهم من أجل استخدام أمثل لهذه الخيارات" (صيام، ع . . ب، ص: (1). ويتم التفريق في مفهوم

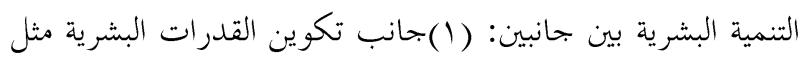

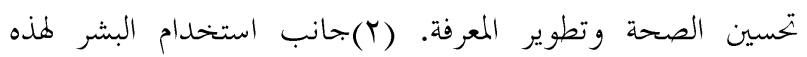
القدرات والمساهمات الفعالة في النشاطات الثقافية والاجتماعية و والسياسية.

ومع تطور الاهتمام بالعمل التطوعي، يمكن للمنظمات غير

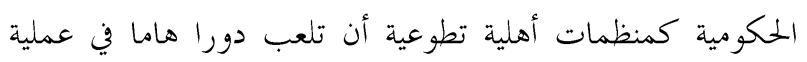

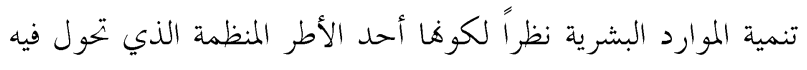

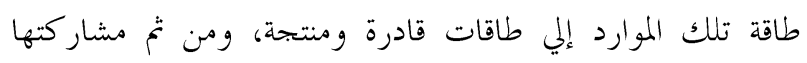

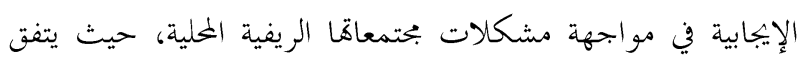

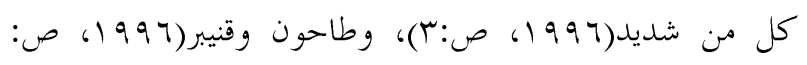

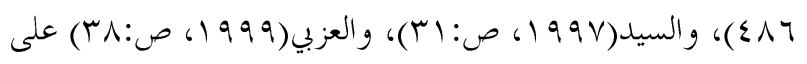

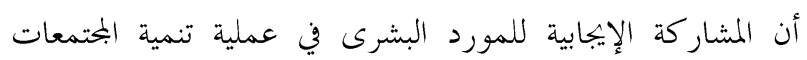

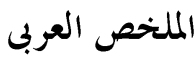

استهدف هذا البحث بصفة رئيسية التعرف على الآثار التعليمية

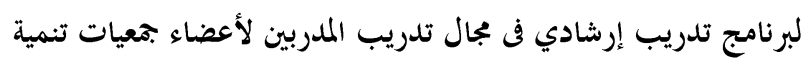

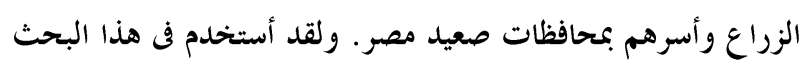

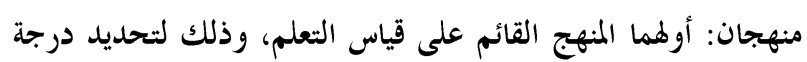

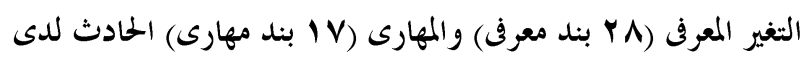

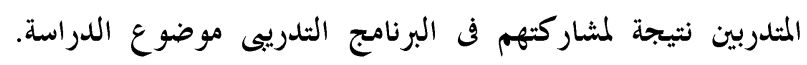

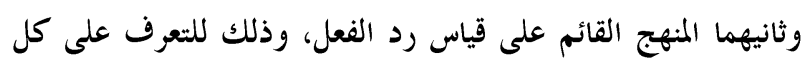

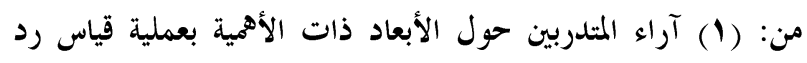

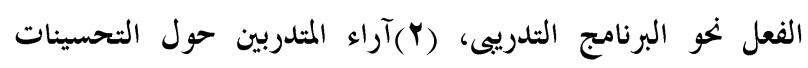

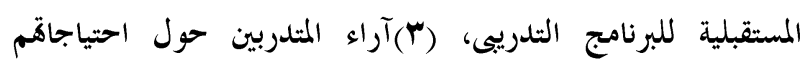
التدريبية المستقبلية. وقد تم جمع بيانات هذا البحث من جميع المتدربين المشاركين فى

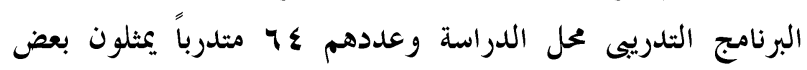

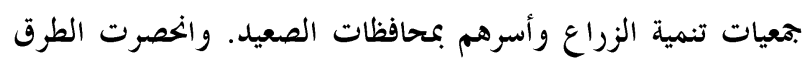

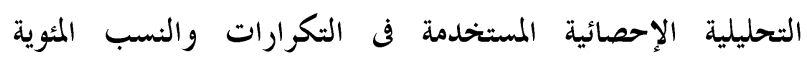

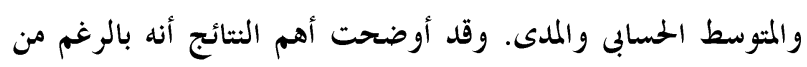

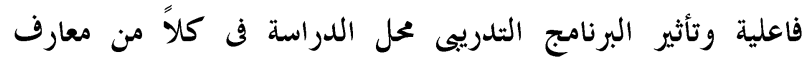

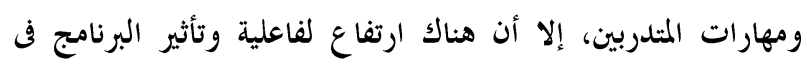

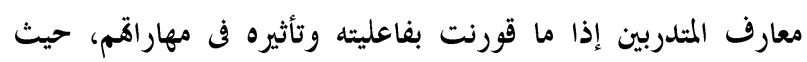

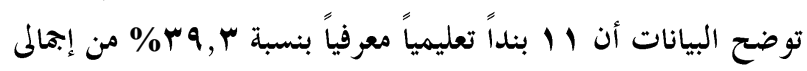

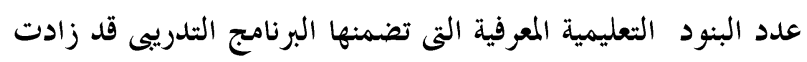
معارف المتدربين بشأفا بعد التدريب بمقدار يزيد عن ضعف المعردية معارفهم 
بشكل أكثر تحديداً عدة مزايا Werther \&Davis (1980, p. 178) يمكن أن تنعكس على المنظمة من التدريب وهى: (1) (1) تحسين الروح المعنوية للعاملين. (r) المساعدة في فهم السياسات داخل المل المنظمة.

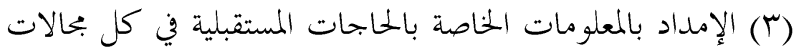

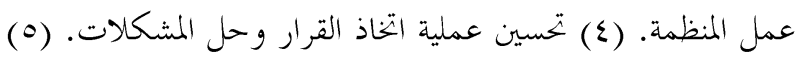
تنمية المهارات القيادية. (7) تحسين قنوات الاتصال داخل الماتين المنظمة.

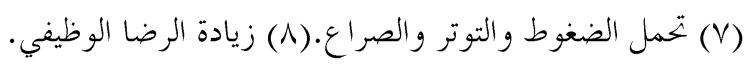
ولأهمية موضوع التدريب تركز الأسس والمبادئ الحديثة للتدريب على إعداد البرامج التدريبية من منطلق ما يسمى بالقدرات

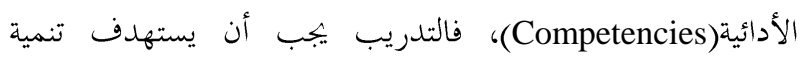

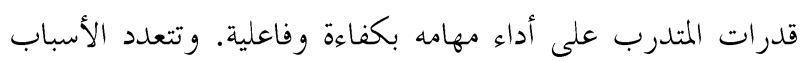

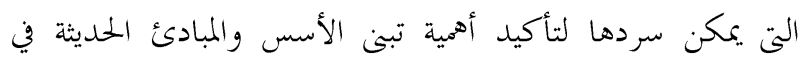

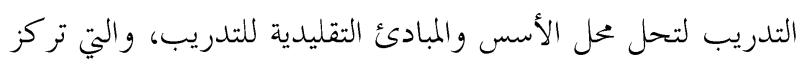

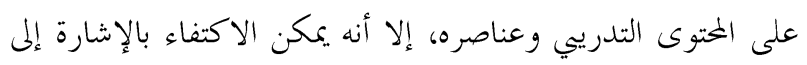

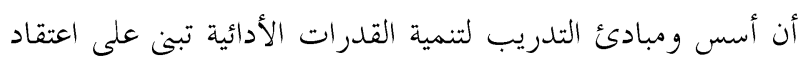

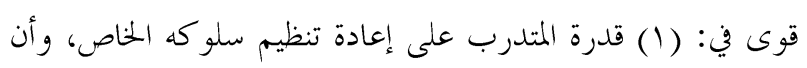

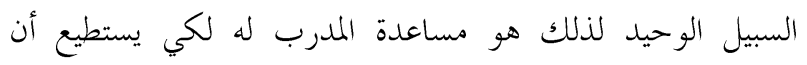

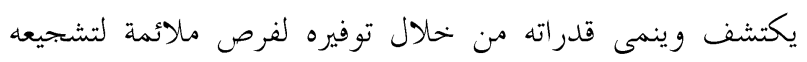

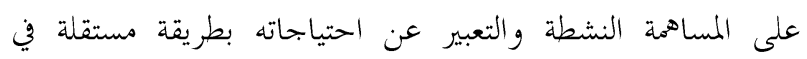

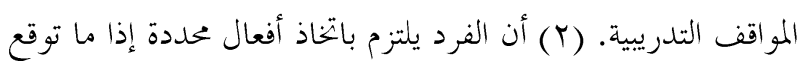

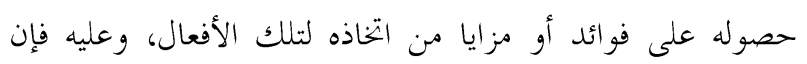
اختيار الفرد للمشاركة في البرنامج التدريي يعتمد على تقدي تلديره للقدرات الأدائية التي سوف يكصل عليها أو يكسنها كنتيجة لتلك لتك

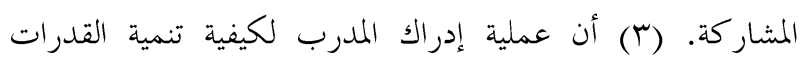
الأدائية للمتدربين تبدأ ببناء علاقة ثقة متبادلة ومشاركة بينه وبينهم إنها

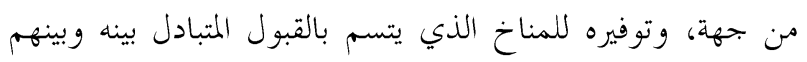

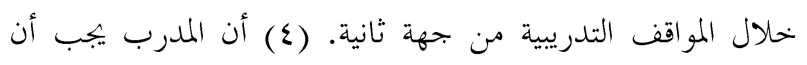

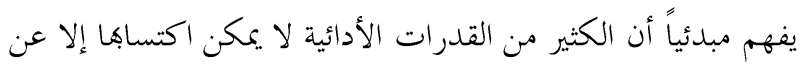

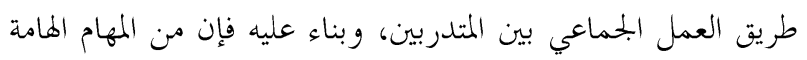
للمدرب العمل على تدريب المتدربين على كيفية تنظيم أنفسهم بطريقة تمكنهم من القيام بعمل مشترك وتكلى وتكوين تفكير جماعي(Kroehnert, (2000) (Klatt, 1999).
الريفية المحلية تؤدي إلى: (1)تنمية روح التعاون بين الأفراد وتوسيع

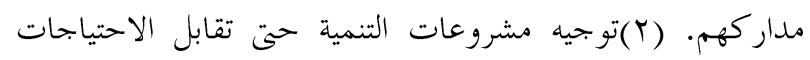

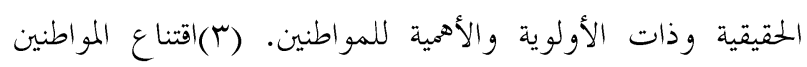

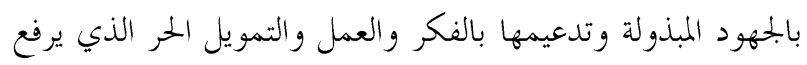

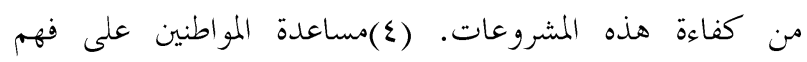
بجتمعاقم وتحديد احتياجاهم ومشكاهلاقم. (0)رفع كفاءة المواطنين

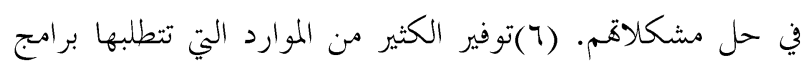
التنمية والتي يمكن تعبئتها محلياً.

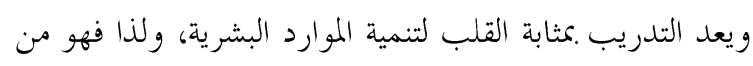

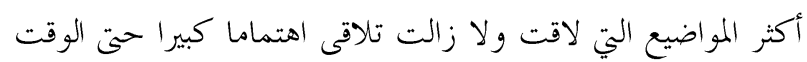

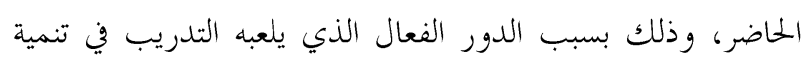
وتطوير الأداء لكافة فئات العاملين. هذا وقد تمع تناول مفهوم التدريب خلال العديد من الكتابات، وقد اتفقت معظم التعاريف التي صيغت لتحديد مفهوم مصطلح التدريب في الجوهر و اختلفت

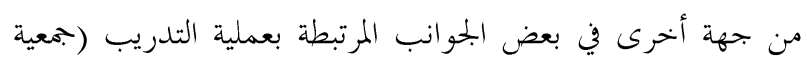

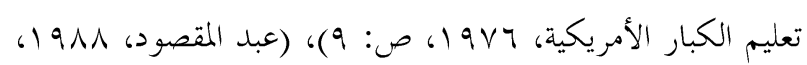

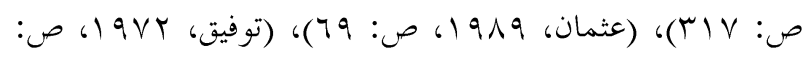

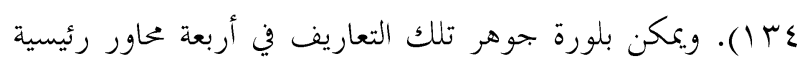
هي:(1) إن التدريب عملية تستهدف إحداث تعديل إيبابي في البناء

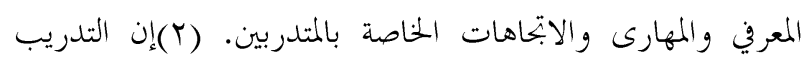
عملية منظمه ومخططه على أساس من التحليل العقلاني للاحتياجات

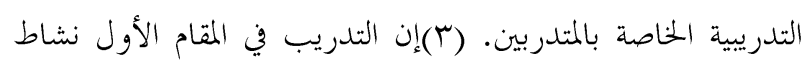

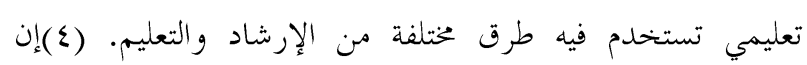

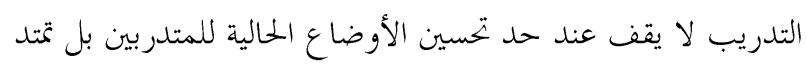

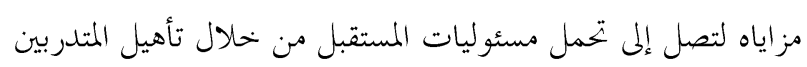
لأعمالهم التي يتوقع منهم القيام هـا في المستقبل.

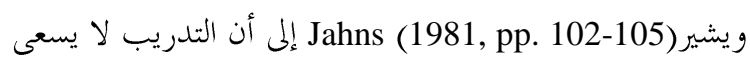
فقط إلى إحداث تنمية لقدرات العاملين لأداء وظائف معينة، وإنما

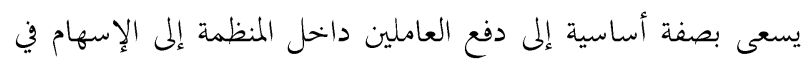

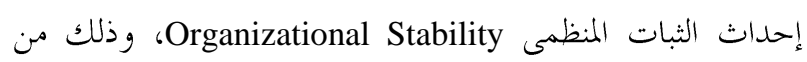
خلال مساعدهم على إدراك الأهداف العامة للمنظمة بشكل أكبر

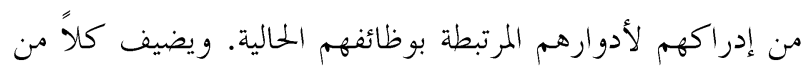


واكتساب المعارف والمهارات التي تؤهل أعضاء تلك الجمعيات للتعامل مع مشككلاقم بفاعلية وكفاءة، سعى المشرو ع لتنفيذ برنامج

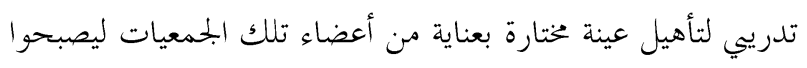

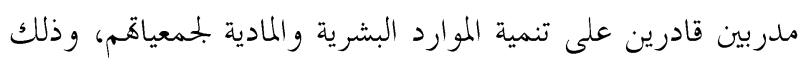

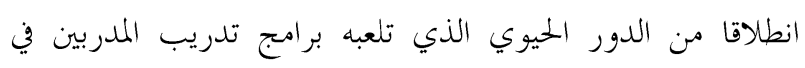
تحقيق الغرض السابق الإشارة إليه. وإذا ما أوخذ في الاعتبار: (1) أن آلية التقويم هي الإطار الفلسفي العام الذي يجب أن يجيط ويرتبط بكل مدخلات وعمليات

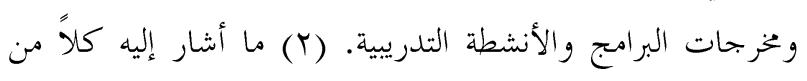

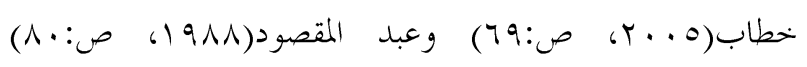

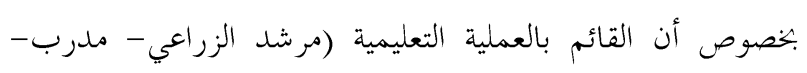

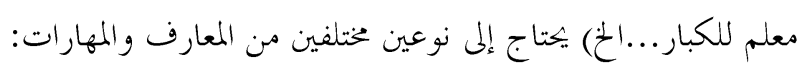

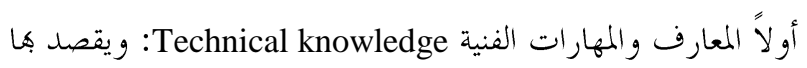
الإلمام التام بالجوانب الفنية للمحتوي التعليمي الذى يقوم بتعليمه،

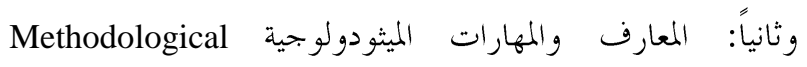
knowledge ويقصد بها الإلمام التام بالجو انب التى تغطى استخدامه ودئه

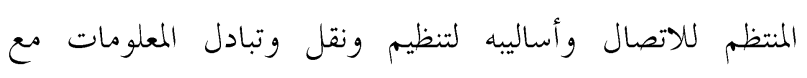

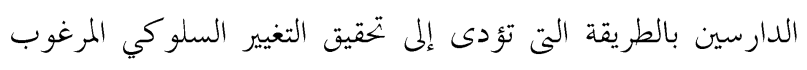
(r) (ما يتطلب معه تدريب المدربين لتنمية قدراتم الاتصالية).

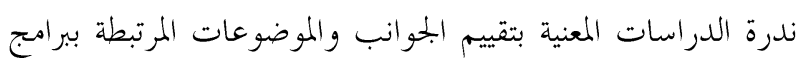

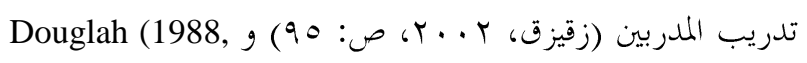
(ع) .p. 2)

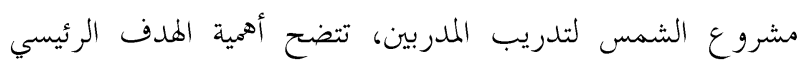
للدراسة الحالية والمتمثل في التعرف على الآثار التعليمية لبرنامج تدريب إرشادي في بحال تدريب المدربين لأعضاء جمعيات تنمية الزراع وأسرهم مكحافظات صعيد مصر. ويمكن تحقيق هذا الهدف الرئيسي من خلال تحقيق الأهداف الفرعية التالية: (1) التعرف على بعض الخصائص الشخصية والمهنية

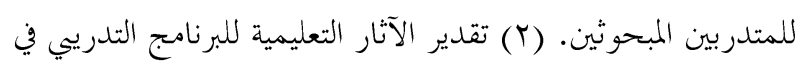

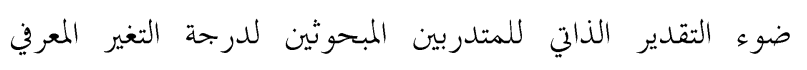

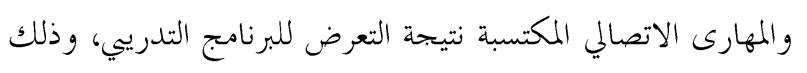

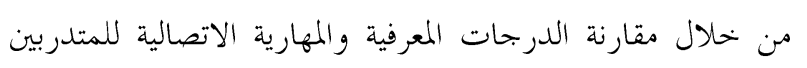

وبإمعان النظر في أهم الأسس والمبادئ الحديثة للتدريب السابق الإشارة إليها، يمكن ملاحظة أها تركز على أهمية تدريب المدربين،

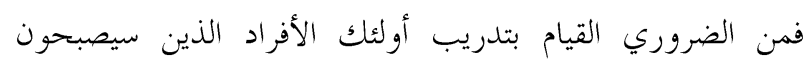

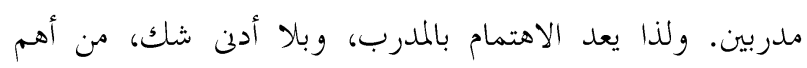
الأولويات التئي يجب أخذها في الاعتبار عند تبنى مفهوم وآليات

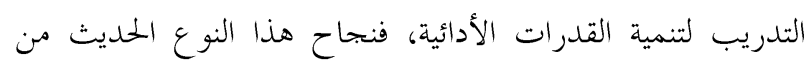

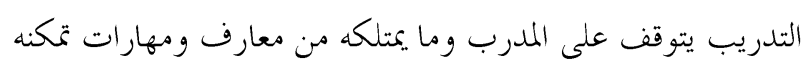
من تنفيذ مقوماته، ولذا فإن اختيار المدربين يجب أن يتم بعني لمناية كبيرة.

وعلى الرغم من أهمية المعارف والمهارات التدريبية للمدربين إلا

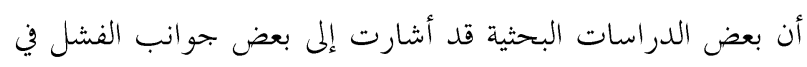

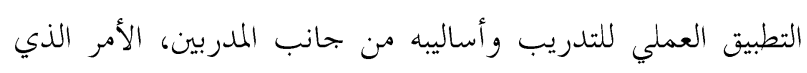

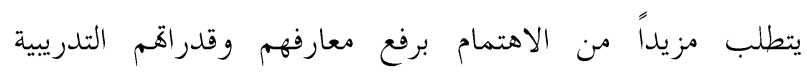
Roling \&Engel, 1991, p.127) المدربين(Training of Trainers (TOT تدريب بحموعة من الأفراد على إدراك جوهر عملية التدريب وكيفية تخطيط وتنفيذ كافة أبعادها منا يكسبهم المعارف والمهارات اللازمة لحسن أدائهم

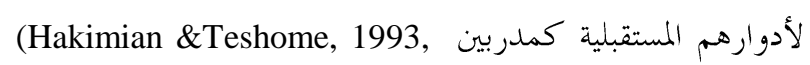
.(p. 6 ومن منطلق كثرة المشاكل التي تعانى منها المجتمعات المحلية الريفية بصعيد مصر بصفة خاصة من جهة، وما سبق الإشارة إليه

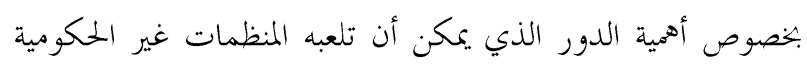

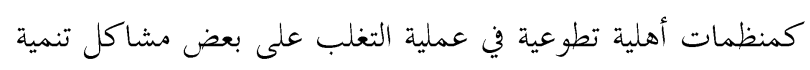

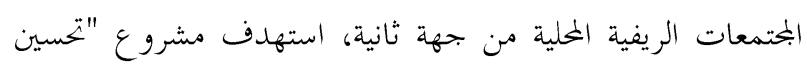
مستوى المعيشة من خلال إدارة مزارعي الحيازات الصغيرة لأنشطتهم الزراعية باستدامة (الشمس)" التابع لهيئة "كير" الدولية

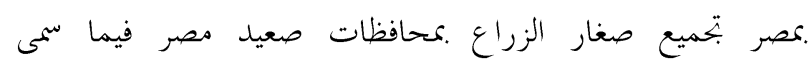

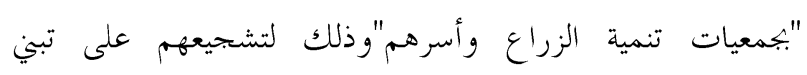

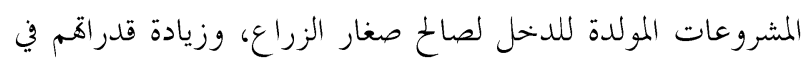
بحال تصدير الحاصلات البستانية. وقد تعدى عدد تلك الجمعيات

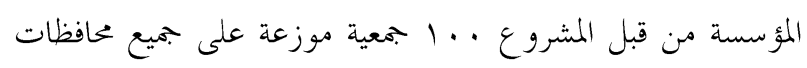

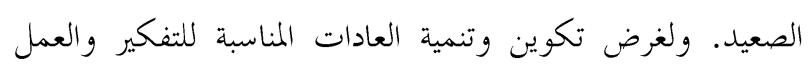


المشكلات)، والأهداف التدريبية (التعريف- المزايا- الخصائص-

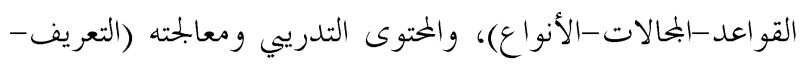

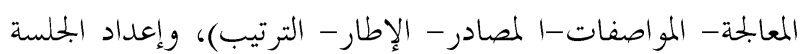

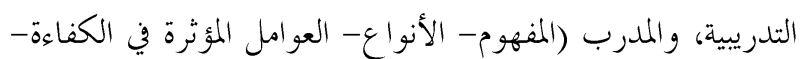

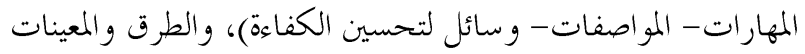
و النشاطات و التمارين التدريبية (فوائد- الاستخدام- أساسيات الاختيار والاستخدام- الخصائص- التصنيف- الأمثلة)، والتقييم

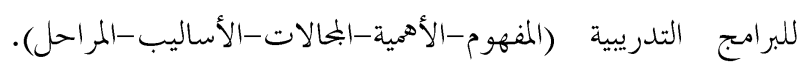
هذا وقد تم الاعتماد على المعارف والمهارات السابق الإشارة إليها في

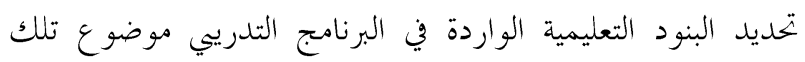
الدراسة.

Saylor مناهج تقييم البرامج التدريبية: لقد اقترح كل من كن Confer (1981 ، \& Associates (1981,pp. 361-362)

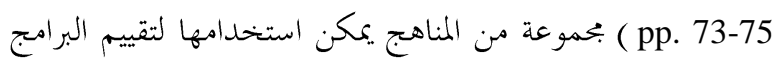
التدريبية، وهى:

(أ) المنهج القائم على قياس التعلم (Learning)، ونعنى به قياس مدى إلمام المتدربين بالمعارف والمهارات التي تم تعرضهم لهات لها أثناء البرنامج التدريي(ماذا تعلم المتدربين من البرنامج التدريي)، ويستخدم في ظل هذا المنهج بحموعة من المقاييس المختلفة للمعرفة والمهارة قبل وبعد البرنامج.

(ب) المنهج القائم على قياس رد الفعل (Reaction)، ويستخدم

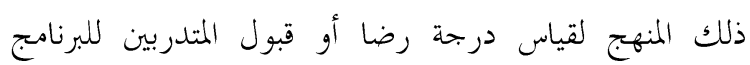
التدريي و كيفية تحسينه من وجهة نظرهم بشكل أكثر من قياس درجة تحقيق أهداف البرنامج، فمن الطبيعي أن يختلف المتدربون

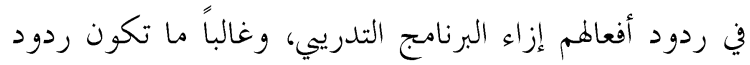
أفعالهم متأثرة بتوقعاهم وبتحارهم السابقة.

(ج) المنهج القائم على أساس السلوك (Behaviour)، و يستخدم ذلك المنهج لقياس التغير الحادث في أداء العمل أو السلوك المهني كنتيجة للبرنامج التدريي، ويتطلب ذلك النوع من القياس ملاحظة وتسجيل وتحليل الأداء الوظيفي للمتدربين من جهة، والقدرة على التمييز بين التغيرات الحادثة نتيجة البرنامج وتلك ولك ولكين التغيرات التئ لا ترجع للبرنامج التدريي.
المبحوثين قبل وبعد تنفيذ البرنامج التدريي. (r) التعرف على ردود

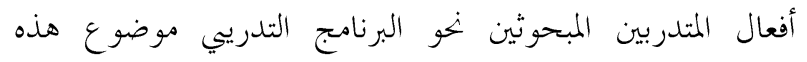

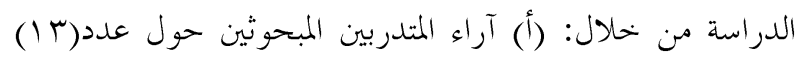

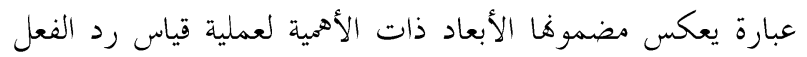
نحو البرنامج التدريي محل الدراسة، و(ب) آراء المتدربين المبحوثين حول التحسينات المستقبلية للبرنامج التدريي، و و(ج) آراء المتدربين المبحوثين حول احتياجاهم التدريبية المستقبلية.

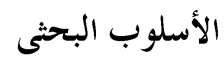

التعريفات الإجر ائية للمصطلحات الرئيسية (1)برنامج تدريب المدربين محل الدراسة: ويقصد بمفهوم تدريب المدربين(Training of Trainers (TOT تدريب بحموعة من الأفراد على إدراك جوهر عملية التدريب وكيفية تخطيط وتنفيذ كافة

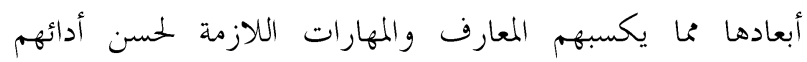

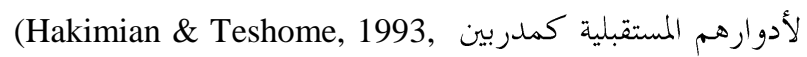
6 .p. 6 ويقصد به في الدراسة الحالية برنامج تدريب المدربين المنظم

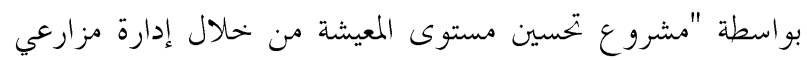

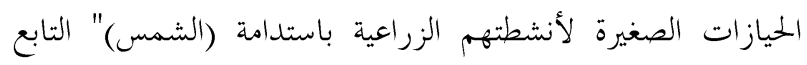

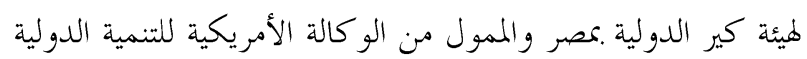

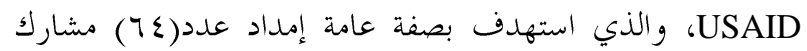
(كعينة مثثلة لبعض جمعيات تنمية الزراع وأسرهم بصعيد مصر)

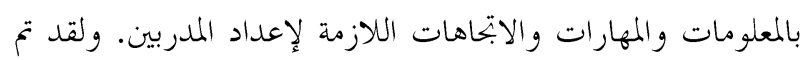

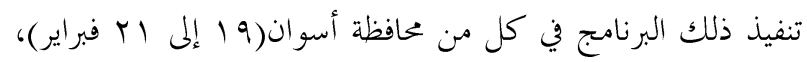

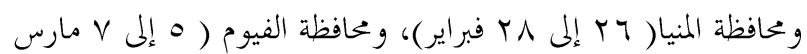
. (Y.. T

(Y) موضوعات برنامج تدريب المدربين محل الدراسة: ويقصد ها

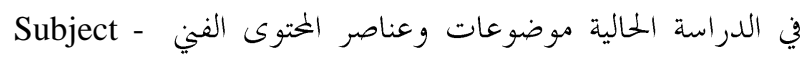
(Matter)

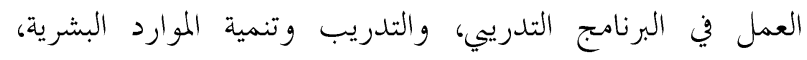
ومفهوم وجوهر ومحاور وفو ائد العملية التدريبية، ومواطن الاختلاف

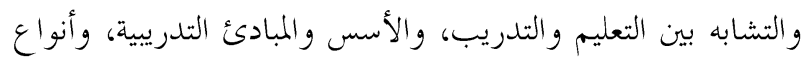

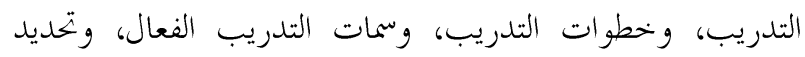
الاحتياجات التدريبية (الأهداف- الأبعاد- الفئات- الأساليب- ونمات 
- آراء المتدربين المبحوثين حول التحسينات المستقبلية للبرنامج

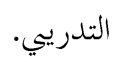
- آراء المتدربين المبحوثين حول احتياجاهم التدريبية المستقبلية. وحدات البحث من أجل تحقيق الهدف الرئيسي للدراسة الحالية والخاص بتحديد الآتار التعليمية لبرنامج تدريب إرشادي في مجال تدريب المدربين

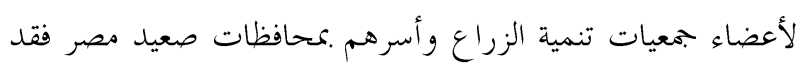

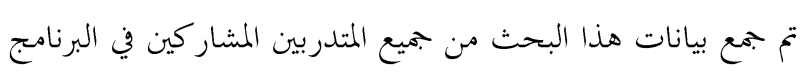

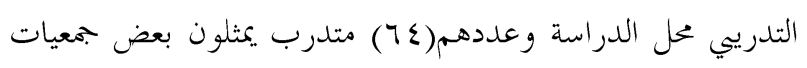
تنمية الزراع وأسرهم بمحافظات الصعيد. أسلوب تجميع وتحليل البيانات جمعت بيانات هذا البحث عن طريق الاستبيان المنفذ جماعياً بالمقابلة الشخصية بعد الانتهاء من البرنامج التدريي محل الدراسة، وقد روعي في تصميم استمارة الاستبيان البساطة و الشمول و التركيز على الجوانب التى تحقق الأهداف البحثية. وتتضمن استمارة الاستبيان أربعة أقسام رئيسية: ينطوى القسم الأول منها على قياس الته

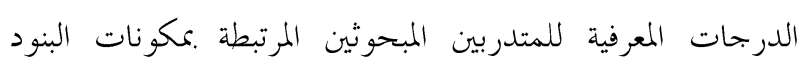

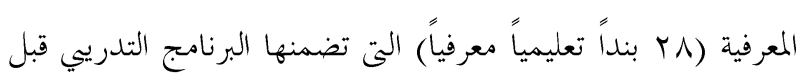
و بعد تنفيذه، واشتمل القسم الثاني منها على قياس الدرجات المهارية

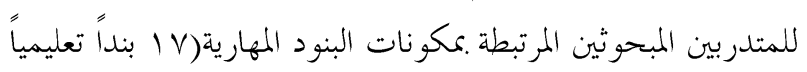

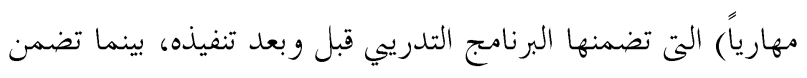

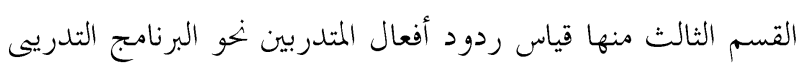

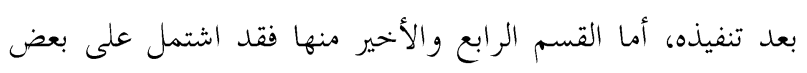
الخصائص الشخصية والمهنية للمتدربين المبحوثين. بعد جمع البيانات ومراجعتها، تم الاستعانة بالحاسب الآلي

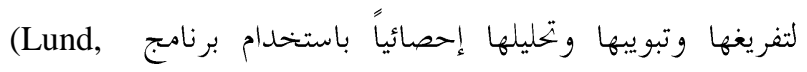
MSUSTATE 1987) ولقد استخدمت الأساليب الإحصائية

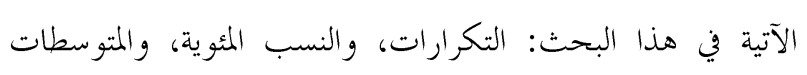

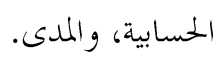

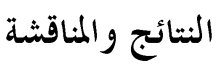

أولاً: بعض الحصائص الشخصية والمهنية للمتدربين المبحوثين
(د) المنهج القائم على قياس النتائج (Results)، ويستخدم هذا المنهج لقياس وتقدير النتائج الإجمالية للبرنامج التدريي (النتائج الملموسة للبرنامج التدريي بالنسبة للعمل). (\&) مناهج تقييم برنامج تدريب المدربين محل الدراسة: ويقصد بها في الدراسة الحالية كلاًّ من: (أ) المنهج القائم على قياس التعلم(Learning): و ويعرف على أنه

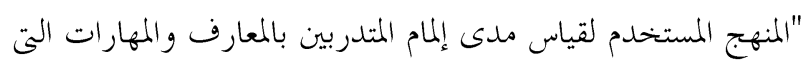

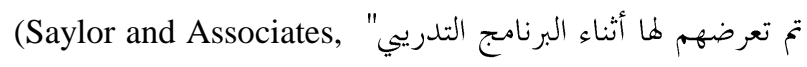
1981, p. 361), (Taylar and Renner 2000, p.30) استخدم هذا المنهج في الدراسة الحالية لتحديد درجة التغير المعرفي والمهارى التدريي الحادث لدى المتدربين كنتيجة لمشاركتهم في

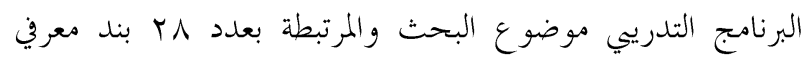

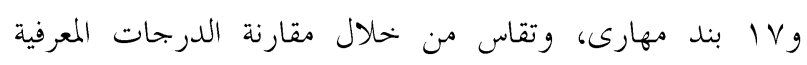
والمهارية التدريبية للمتدربين المبحوثين قبل وبعل وتنداين تنفيذ البرنامج

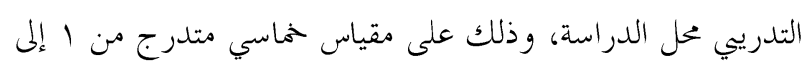

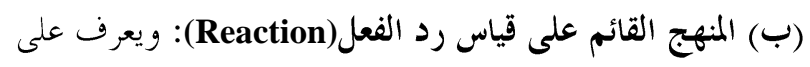

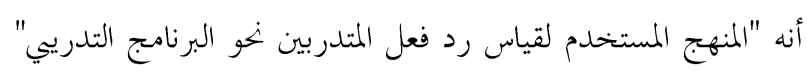

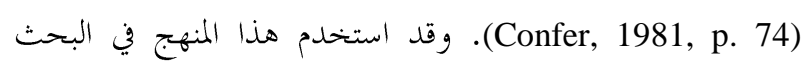
الحالي للتعرف على ردود أفعال المتدربين نحو البرنامج التدريي موضوع هذه الدراسة، وذلك من خلال: ردود آلكال - آراء المتدربين المبحوثين حول عدد (س ال)عبارة يعكس مضموهنا

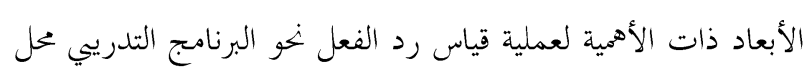

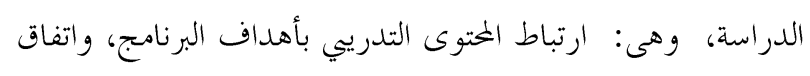

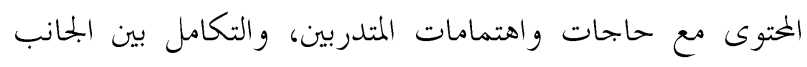
النظري والعملي للمحتوى، و الرضا عن كمية معلومات البرنامج

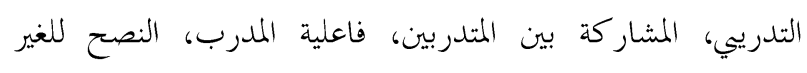
بحضور البرنامج التدريي، فرص استخدام معارف ومهارات

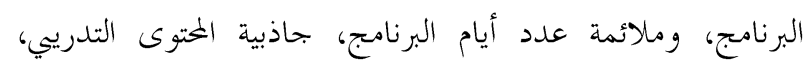

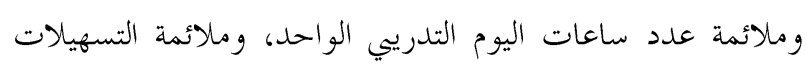

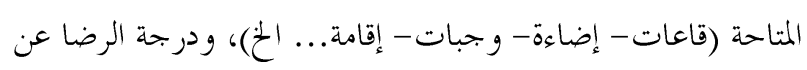

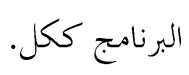




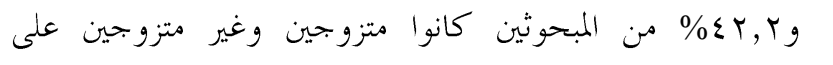

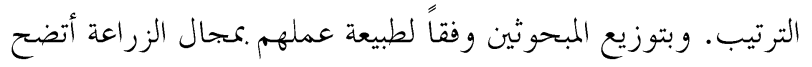

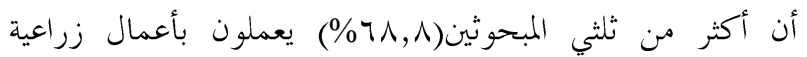

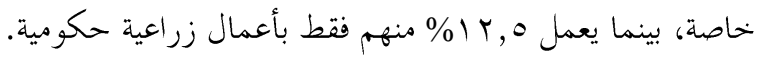

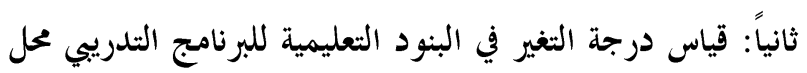

$$
\text { الدراسة }
$$

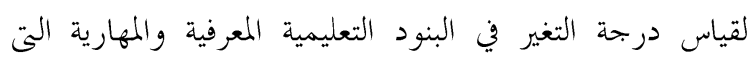
تضمنها البرنامج التدريي موضوع هذا البحث تم إنجراء الآتي: - سؤال المتدربين المبحوثين عن تقديرهم الذاتي لدرجة إلمامهم

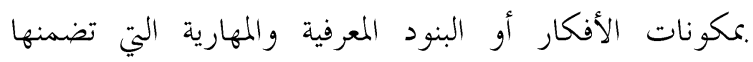

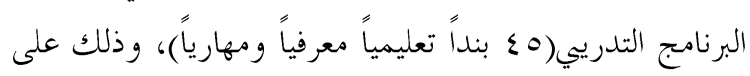

$$
\text { مقياس متدرج من إإلى ه. }
$$

- حساب المتوسط الحسابي لكل بند تعليمي قبل التدريب.

- حساب المتوسط الحسابي لكل بند تعليمي بعد التدريب.
توضح البيانات الواردة بجدول رقم (1) توزيع المتدربين

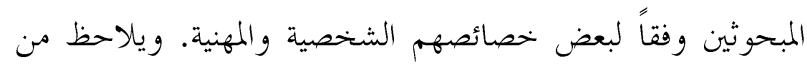

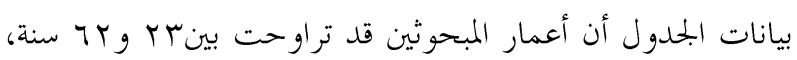

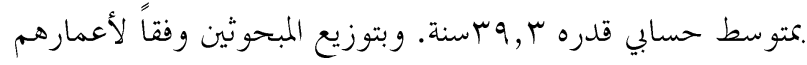

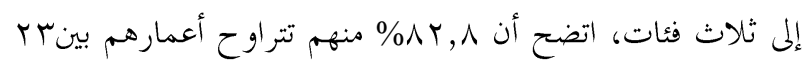

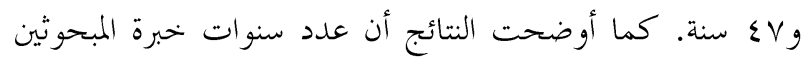

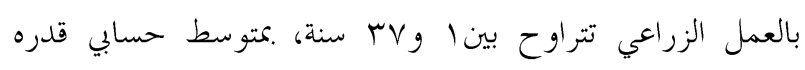

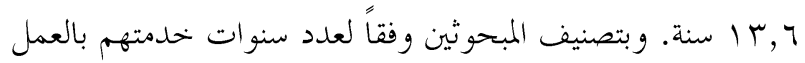

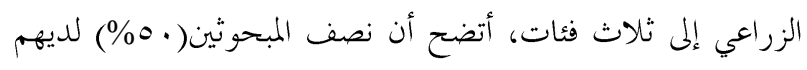

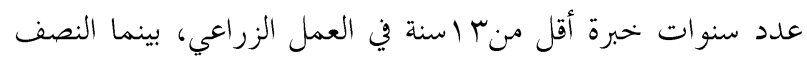

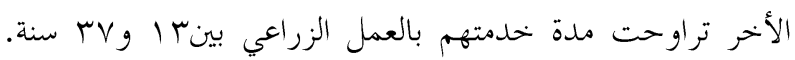

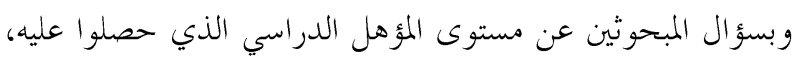

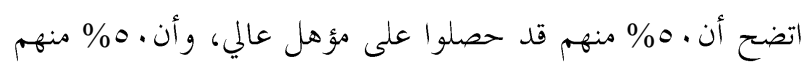

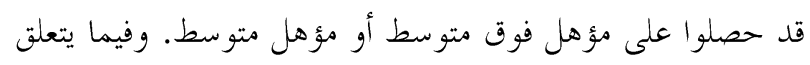

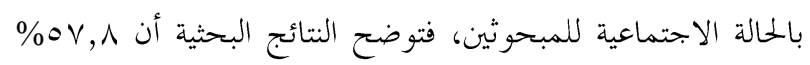

جدول رقم ا. توزيع المبحوثين وفقاً لبعض الخصائص الشخصية والمهنية

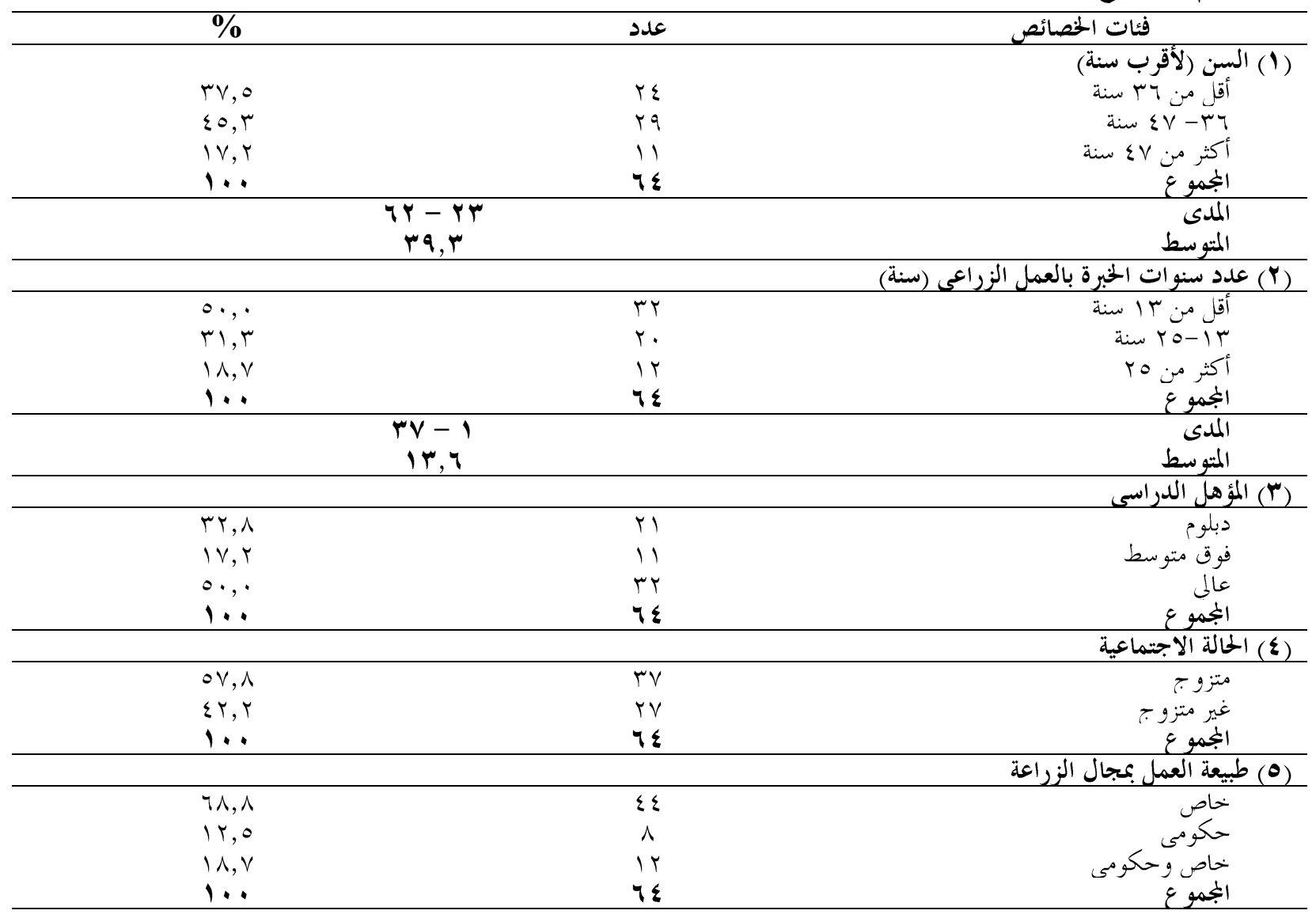


المتحدث بعد عرض فكرة ما وبين زيادة درجة تركيز المستمعين"

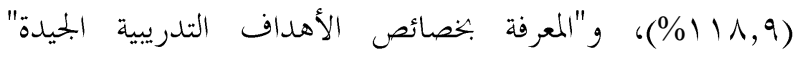

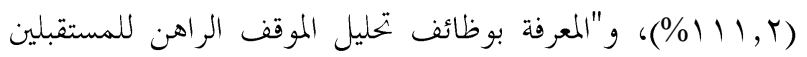

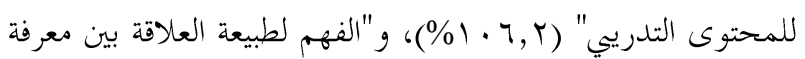

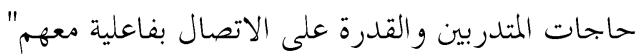
(气, ه • 1\%)، و"المعرفة بالأمور التنظيمية الخاصة بمعالجة الرسائل

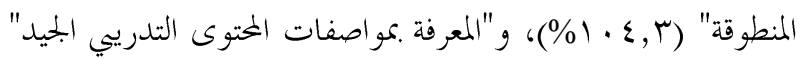

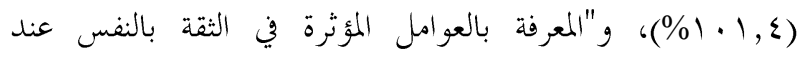

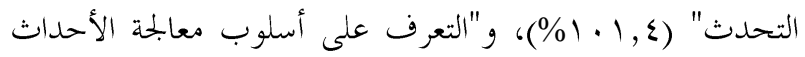

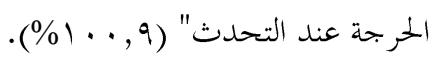

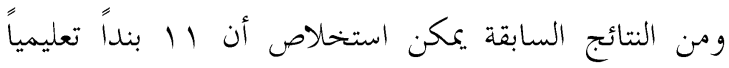

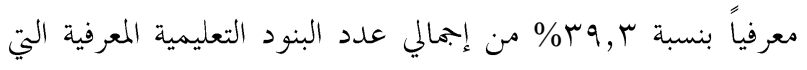
تضمنها البرنامج التدريي محل الدراسة قد زادت معارف المتدربين بشأها بعد التدريب بمقدار يزيد عن ضعف معارفهم بشأها قبل

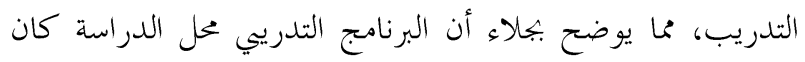
عظيم الأثر على مستوى معارف المتدربين في بحال تدريب المدربين. (Y) قياس درجة التغير في البنود التعليمية المهارية: لقياس درجة

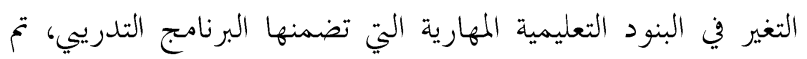

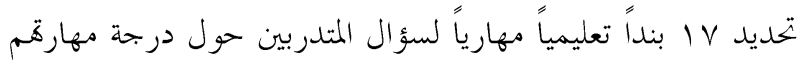
المرتبطة مضمون كل بند تعليمي مهارى قبل وبعد تنفيذ البرنامج

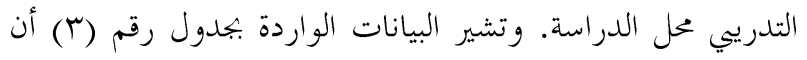
قيمة المتوسط الحسابي للبنود التعليمية المهارية قبل تنفيذ البرنامج التدريي قد تراوحت بين VV, I 1 درجة في حده الأدلن والخاص ببند

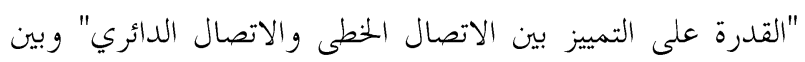
ا ب, r, درجة في حده الأقصى والخاص ببند "القدرة على استخدام السبورة الورقية"، بينما تراوحت قيمة المتوسط الحسابي للبنود

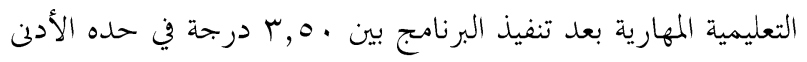

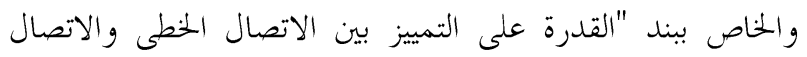

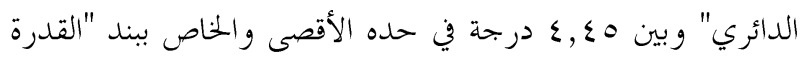

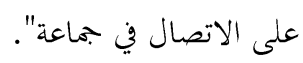

-حساب الفرق بين متوسطي كل بند تعليمي قبل وبعد التدريب. - حساب النسبة المئوية للتغير في كل بند تعليمي عن طريق قسمة الفرق بين متوسطي البند التعليمي قبل وبعد التدريب على بلى

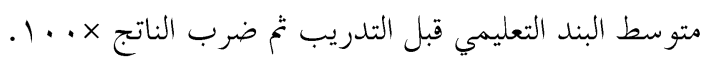
(1)قياس درجة التغير في البنود التعليمية المعرفية: لقياس درجة

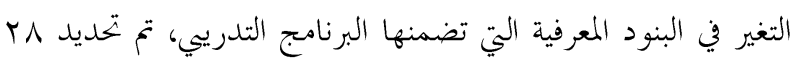

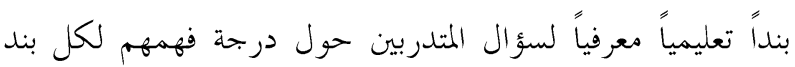
تعليمي معريي قبل وبعد تنفيذ البرنامج التدريي محل الدراسة. وتوضح البيانات الواردة بجدول رقم (r) أن قيمة المتوسط الحسابي للبنود التعليمية المعرفية قبل تنفيذ البرنامج التدريي قد تراوحت بين ع, إ درجة في حده الأدنى والخاص ببندي "المعرفة بالأمور التنظيمية الخاصة بمعالجة الرسائل المنطوقة" و "المعرفة بأساليب علاج ولاج ظاهرة تصفح المستمعين بالعين بدلاً من الاتصال معهم بالعين" و بين

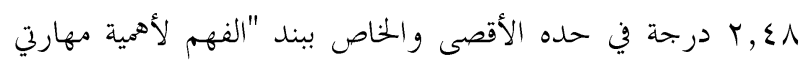
التحدث والإنصات في عملية التدريب"، في حين تراوح المتوسط

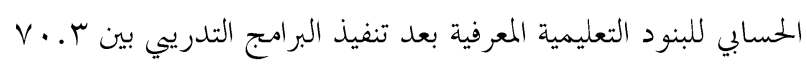

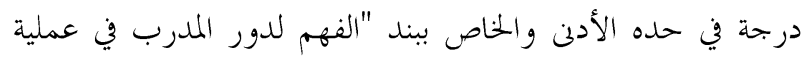

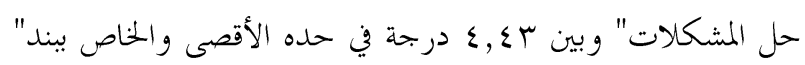

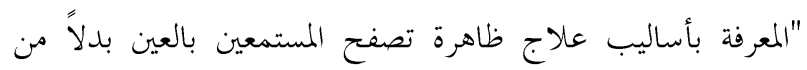

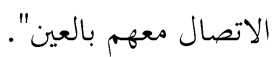
وبحساب النسبة المئوية للتغير في كل بند تعليمي معرفي عن طريق قسمة الفرق بين متوسطي البند التعليمي المعرفي قبل وبعد التدريب

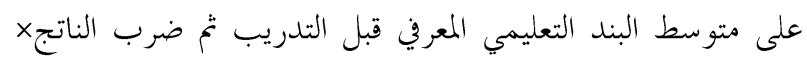

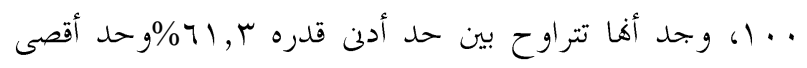

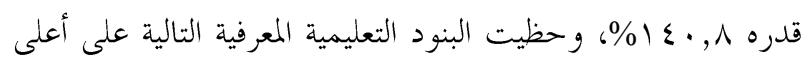

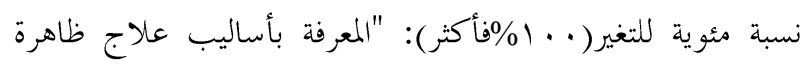

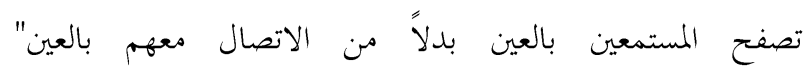

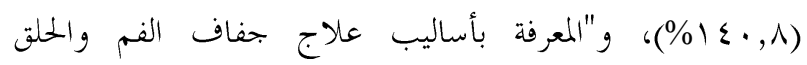
وانخفاض الصوت عند بداية التحدث أمام بحموعة من الأفراد"

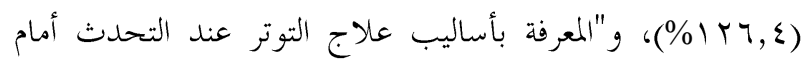

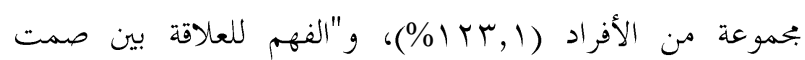


جدول رقم ץ. مقارنة المتوسط الحسابي قبل وبعد التدريب بالنسبة للبنود التعليمية المعرفية

\begin{tabular}{|c|c|c|c|c|c|}
\hline 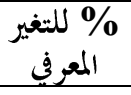 & المتوسطين & المتوسط بعد & المتوسط قبل & البنود التعليمية المعرفية & r \\
\hline$V T, Y$ & $1, \wedge 9$ & $\varepsilon, r V$ & $r, \Sigma \wedge$ & الفهم لأهمية مهارتق التحدث والإنصات في عملية التدريب. & 1 \\
\hline $1 \cdot 0, \varepsilon$ & $r, 1 \varepsilon$ & $\varepsilon, 1 \vee$ & $r, \cdot r$ & الاتصهم لطبيعة العلاقة بين معرفة حاجات المتدربين والقدرة على & r \\
\hline $1 \cdot 7, r$ & $r, \cdot \varepsilon$ & $\uparrow, 97$ & $1,9 r$ & التدريئ بوظائف تحليل الموقف الراهن للمستقبلين للمحتوى & $r$ \\
\hline $71, r$ & $1, \varepsilon \varepsilon$ & $r, v q$ & r, ro & المعرفة بمو اصفات المدرب الجيد. & $\varepsilon$ \\
\hline $111, r$ & $r, 1 \wedge$ & $\varepsilon, 1 \leqslant$ & 1,97 & المعرفة بخصائص الأهداف التدريبية الجيدة. & 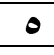 \\
\hline 90 & $T, \cdot V$ & $\varepsilon, Y_{0}$ & $r, 1 \wedge$ & الفهم لأهمية تحديد حاجات المتدربين في عملية التدريب. & 7 \\
\hline $\mid r T, 1$ & $r, \varepsilon$ & $\varepsilon, \mu_{0}$ & 1,90 & المعرفة بأساليب علاج التوتر عند التحدث أمام بحموعة من & $\mathrm{V}$ \\
\hline $1.1, \varepsilon$ & $r, 1$ & $\varepsilon, 1 V$ & $r, \cdot V$ & المعرفة بمو اصفات الختوى التدرييى الجيد. & $\Lambda$ \\
\hline 99 & r,Ir & $\varepsilon, \cdot V$ & 1,90 & المتهربين لأهمية تأسيس عملية تحديد الحاجات و أهميتها النسبية على & 9 \\
\hline $1.1, \varepsilon$ & Y,IV & $\varepsilon, r_{1}$ & $r, 1 \leqslant$ & المعرفة بالعو امل المؤثرة في الثقة بالنفس عند التحدث. & 1. \\
\hline 71,7 & $1, \sum 1$ & $r, v \cdot$ & $r, r q$ & الفهم لدور المدرب في عملية حل المشكلات. & 11 \\
\hline $1 \cdot \varepsilon, r$ & 1,94 & $r, \vee \tau$ & $1, \wedge \varepsilon$ & المعرفة بالأمور التنظيمية الخاصة بمعالجة الرسائل المنطوقة. & IT \\
\hline Vo & 1,10 & $\varepsilon, r_{1}$ & $r, \Sigma T$ & المعرفة بمهارات الاتصال الرئيسية. & 14 \\
\hline 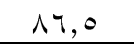 & $r, .0$ & $\varepsilon, \varepsilon Y$ & $r, r V$ & المعرفة بمظاهر التوتر عند التحدث أمام بحموعة من الأفر اد. & $1 \varepsilon$ \\
\hline $1 \times 4, \varepsilon$ & $r, \varepsilon \varepsilon$ & $\varepsilon, r v$ & 1,94 & 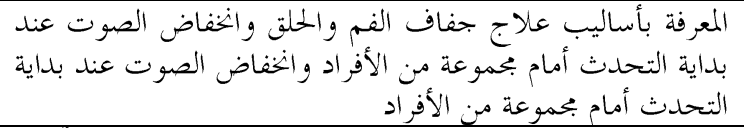 & 10 \\
\hline $1 \varepsilon \cdot, \wedge$ & r,० & $\varepsilon, \varepsilon \Gamma$ & $1, \wedge \varepsilon$ & الاتصعال بعجهم بالعين. علاج ظاهرة تصفح المستمعين بالعين بدلا من & 17 \\
\hline 111,9 & $r, r q$ & $\varepsilon, \varepsilon$. & $r, \cdot 1$ & درجة تركيز المستمعين. & iv \\
\hline $1 \cdots, 9$ & $r, 11$ & $\varepsilon, r$. & $r, .9$ & التعرف على أسلوب معالجة الأحداث الحرجة عند التحدث. & 11 \\
\hline $91, \varepsilon$ & Y,,$Y$ & $\varepsilon, r \mu$ & $r, r_{1}$ & الفهم لمنحني التركيز عند المستمعين. & 19 \\
\hline $9 \xi, \Gamma$ & $1,9 \mathrm{~V}$ & $\varepsilon, \cdot 1$ & $r, .9$ & المعرفة بإجر اءات التعامل مع أسئلة المتدربين. & $r$. \\
\hline $91, \mathrm{~V}$ & r, $\cdot$ & $\varepsilon, 1 \wedge$ & $r, 1 \wedge$ & 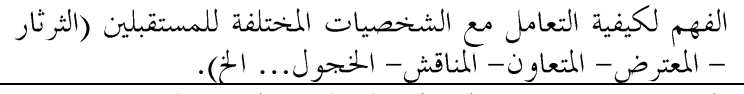 & YI \\
\hline$\Lambda T, r$ & $1,1 \Lambda$ & $\varepsilon, 1 V$ & r, rq & المعرفة بمز ايا ومعوقات المشار كة الفعالة في المواقف التعليمية. & rr \\
\hline$\vee \vee, \Lambda$ & $1, \Lambda \mu$ & $\varepsilon, 1 \wedge$ & r, ro & المعرفة بفو ائد استخدام الطرق و المعينات التعليمية. & $r r$ \\
\hline$\wedge 9, \varepsilon$ & $r, \cdot r$ & $\varepsilon, r \wedge$ & $r, r\}$ & المعرفة بأساسيات اختيار واستخدام الطرق و المعينات التعليمية. & Y $\varepsilon$ \\
\hline 90,7 & $r, 1 \leqslant$ & $\varepsilon, r V$ & tr, & المعرفة بكز ايا الشفافات وجههات العرض فوق الرأس. & Yo \\
\hline$\wedge \varepsilon, 7$ & 1,99 & $\varepsilon, r \varepsilon$ & r, ro & المعرفة بأنو اع السبورة الورقية. & Yy \\
\hline $9 \varepsilon, Y$ & T,IT & $\varepsilon, r V$ & T, ro & المعرفة بمز ايا وعيوب السبورة الورقية. & rV \\
\hline$v_{0, q}$ & $1, \wedge 7$ & $\varepsilon, r$ & $r, \Sigma 0$ & المعرفة كمزايا أفلام الفيديو التعليمية. & rᄉ \\
\hline
\end{tabular}

(r) أن البنود التعليمية المهارية التالية قد حظيت بأعلى نسبة مئوية

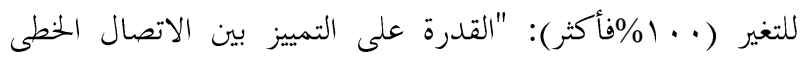

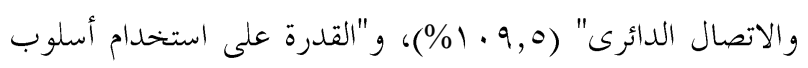

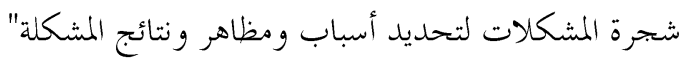

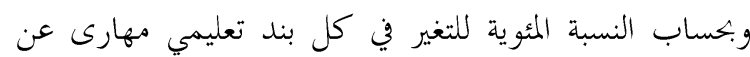

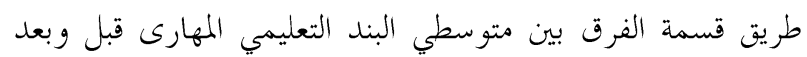

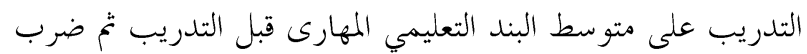

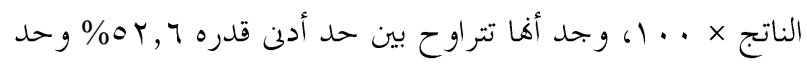

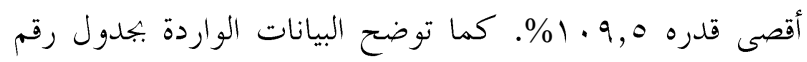


جدول رقم ب. مقارنة المتوسط الحسابي قبل وبعد التدريب بالنسبة للبنود التعليمية المهارية

\begin{tabular}{|c|c|c|c|c|c|}
\hline 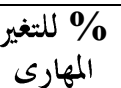 & المتوق بين & المتوسط بعد & المتوسط قبل & البنود التعليمية المهارية & r \\
\hline $1.0,1$ & $r, \cdot r$ & $r, 97$ & $1,9 \pi$ & القدرة على صياغة الأهداف الأدائية أو السلو كية. & 1 \\
\hline $1.9,0$ & $1, \wedge r$ & $r, 0$. & $1,7 \mathrm{~V}$ & القدرة على التمييز بين الاتصال الخطى والاتصال الدائري. & $r$ \\
\hline$\wedge \uparrow, \varepsilon$ & $1,9$. & $\varepsilon, 1$. & $r, r$. & القدرة على استخدام أساليب زيادة القدرة على الاتصال بالعين. & $r$ \\
\hline $7 \cdot, 9$ & 1,07 & $\varepsilon, 10$ & $r, 09$ & القدرة على إدارة الحوار والمناقشة & $\varepsilon$ \\
\hline$T \wedge, \vee$ & $1, \vee 7$ & $\varepsilon, r$ r & $r, 07$ & القدرة على استعمال الصوت بشكل أكثر فعالية. & 0 \\
\hline$\wedge \varepsilon, 9$ & $1, \wedge 1$ & $\varepsilon, 1\}$ & $r, r$ & القدرة على توجيه الأسئلة خلال عملية التدريب. & 7 \\
\hline$\vee q, \vee$ & 1,10 & $\varepsilon, 1 \vee$ & T,H & القدمة على ملى تحديد مزايا وعيوب المتحدث عند التحدث أمام & $\mathrm{V}$ \\
\hline$\Lambda \bullet, \Gamma_{1}$ & $1, \wedge 7$ & $\varepsilon, \cdot \varepsilon$ & $r, 1 \Lambda$ & القدرة على استيعاب معانى الرموز السمعية والبصرية. & $\Lambda$ \\
\hline$\vee q, r$ & $1, V Y$ & $r, \wedge q$ & $r, I V$ & القدرة على الإعداد الجيد للمحتوى التدريى. & 9 \\
\hline 90,0 & 1,91 & r,qr & $r, \cdot 1$ & القدرة على إدارة جلسات العصف الذهني. & 1. \\
\hline 79,0 & 1,79 & $\varepsilon, 1 \mathrm{~L}$ & $r, \varepsilon r$ & القدرة على استخدام بعض أساليب تحديد الحاجات و المشاكل. & 11 \\
\hline $1 \cdot \wedge, 1$ & r, rV & $\varepsilon, r V$ & $r, 1$. & ومظاهر ونتائج المشكلةمة أسلوب شجرة المشكلات لتحديد أسباب & ir \\
\hline 74 & $1, \mathrm{VV}$ & $\varepsilon, \xi 0$ & $r, T \Lambda$ & القدرة على الاتصال في جماعة. & 14 \\
\hline$\wedge १, \Upsilon$ & $r, \cdot r$ & $\varepsilon, \uparrow \wedge$ & $r, r_{T}$ & مهارات- البحاهات). التمييز بين بحالات الأهداف التعليمية (معارف- & $1 \varepsilon$ \\
\hline $9 \leq, 1$ & $r, \cdot \wedge$ & $\varepsilon, r_{q}$ & $r, Y_{1}$ & القدرة على استخدام الشفافيات وجهاز العرض فوق الرأس. & 10 \\
\hline OY,, & $1, \Sigma \Lambda$ & $\varepsilon, r q$ & $r, \Lambda 1$ & القدرة على استخدام السبورة الورقية. & 17 \\
\hline$\Delta V, \Lambda$ & $1, \mu_{4}$ & $r, v 1$ & T,ro & القدرة على استخدام أفلام الفيديو التعليمية. & IV \\
\hline
\end{tabular}

(1) آراء المثدربين المبحوثين حول الأبعاد ذات الأهمية لعملية قياس رد الفعل نحو البرنامج التدريبي: تح تحديد با عبارة للتعرف

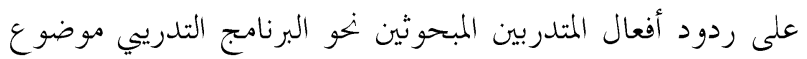
هذه الدراسة، ويعكس مضمون تلك العبارات الأبعاد ذات الأهمية لعملية قياس رد الفعل نحو البرنامج التدريي، وهى: ارتباط المتوى

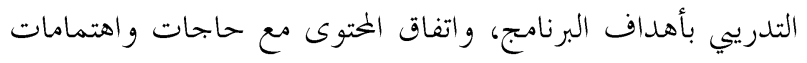

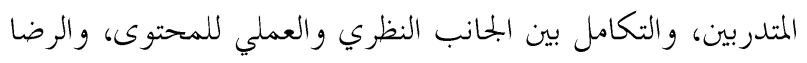
عن كمية معلومات البرنامج التدريي، المشاركة بين المتدربين، فاعلية المدرب، النصح للغير بكضور البرنامج التدريي، فرص استخدام معارف ومهارات البرنامج، وملائمة عدد أيام البرنامج، جاذبية الختوى التدريي، وملائمة عدد ساعات اليوم التدريي الواحد، وملائمة التسهيلات المتاحة(قاعات- إضاءة- وجبات- إقامة ...

$$
\text { الخ)، ودرجة الرضاعن البرنامج ككل. }
$$

وبإمعان النظر في البيانات الواردة بجدول رقم (ع) يتضح بجلاء

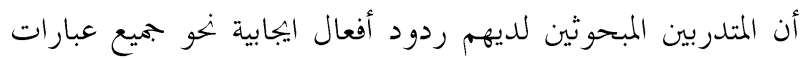

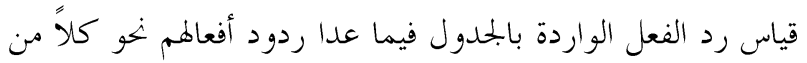

( ( • (1\%)، و "القدرة على صياغة الأهداف الأدائية أو السلو كية"

$$
\cdot(\%) \cdot 0,1)
$$

وعلى الرغم من فاعلية وتأثير البرنامج التدريي محل الدراسة في

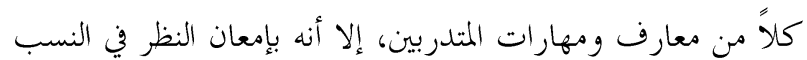

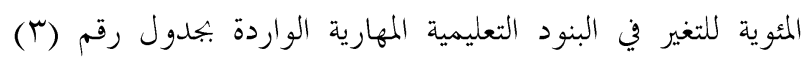
ومقارنتها بالنسب المئوية للتغير في البنود التعليمية المعرفية الواردة بجدول رقم (r) يتضح ارتفاع فاعلية وتأثير البرنامج في معارف

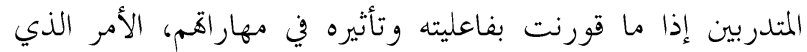
يشير إلى أهمية الاهتمام بالجوانب المرتبطة برفع القدرات أو المهارات وخاصة في إطار برامج تدريب المدربين. ثالثاً: قياس ردود أفعال المتدربين نحو البرنامج التدريبي استخدم منهج قياس رد الفعل في البحث الحالي للتعرف على لى لفي ردود أفعال المتدربين نهو البرنامج التدريي موضوع هذه الدراسة،

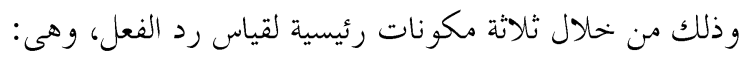




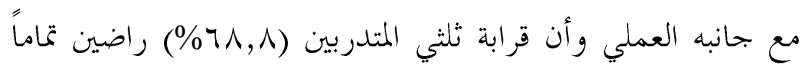
عن كمية المعلومات التي حصلو اعليها من محتوى البرنامج التدريي.

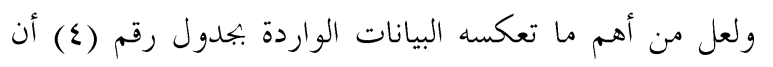
\% १, 1

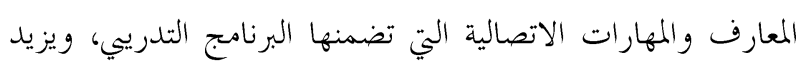

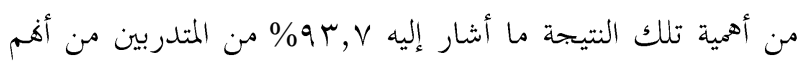
سوف ينصحون غيرهم بحضور البرنامج التدريي محل الدراسة.

جدول رقم ع. توزيع المتدربين وفقاً لردود فعلهم نهو البرنامج التدريبي

\begin{tabular}{|c|c|c|c|c|c|c|c|}
\hline \multicolumn{8}{|c|}{ أبعاد ردود فعل المتدربين نحو البرنامج التدريى } \\
\hline & \multicolumn{2}{|c|}{ غير مرتبط } & \multicolumn{2}{|c|}{ مرتبط لحد ما } & \multicolumn{2}{|c|}{ مرتبط تماما } & \multirow{3}{*}{ (1) ارتباط الختوى بأهداف البرنامج. } \\
\hline & $\%$ & العدد & $\%$ & العدد & $\%$ & العدد & \\
\hline & - & - & $1 \varepsilon, 1$ & 9 & 10,9 & 00 & \\
\hline & \multicolumn{2}{|c|}{ غير متفق } & \multicolumn{2}{|c|}{ متفق لحد ما } & \multicolumn{2}{|c|}{ متفق تماما } & \multirow{3}{*}{ واهتمامات المتندربين. الختوى التدريي مع حاجات } \\
\hline & $\%$ & العدد & $\%$ & 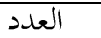 & $\%$ & 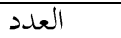 & \\
\hline & - & - & 10,7 & 1. & $\Lambda \varepsilon, \varepsilon$ & $0 \leqslant$ & \\
\hline & \multicolumn{2}{|c|}{ غي متكامر } & \multicolumn{2}{|c|}{ متكامل لحد ما } & \multicolumn{2}{|c|}{ متكامل تماما } & \multirow{3}{*}{ للمّحتوى التكامل بين الجحانب النظري والعملي } \\
\hline & $\%$ & العدد & $\%$ & 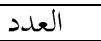 & $\%$ & 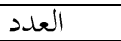 & \\
\hline & 1,7 & 1 & $r \varepsilon, r$ & Tr & $7 \varepsilon, 1$ & $\sum 1$ & \\
\hline & \multicolumn{2}{|c|}{ غير راضب } & \multicolumn{2}{|c|}{ راضى لحد ما } & \multicolumn{2}{|c|}{ راضى تماما } & \multirow{3}{*}{ عليها نتيجة لتعرضك كمية المعلومات التبرتي حصلت } \\
\hline & $\%$ & العدد & $\%$ & العدد & $\%$ & العدد & \\
\hline & \multirow{2}{*}{\multicolumn{2}{|c|}{ لم ميساعد }} & $r, r$ & $r$. & 71,1 & $\varepsilon \varepsilon$ & \\
\hline & & & \multicolumn{2}{|c|}{ ساعد لحد ما } & \multicolumn{2}{|c|}{ ساعد تماما } & \multirow{3}{*}{ المششاركة بين المتدربين. البرنج التدريي في زيادة } \\
\hline & $\%$ & العدد & $\%$ & العدد & $\%$ & 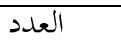 & \\
\hline & $\begin{array}{llll}- & & & \\
\end{array}$ & $\begin{array}{llll}- & & & \\
\end{array}$ & $I V, Y$ & 11 & $\Lambda Y, \Lambda$ & or & \\
\hline & \multicolumn{2}{|c|}{ غير فعال } & \multicolumn{2}{|c|}{ فعال بشكل متو سط } & \multicolumn{2}{|c|}{ فعال بشكل كبير } & \multirow{3}{*}{ (7) التقدير لفاعلية المدرب. } \\
\hline & $\%$ & العدد & $\%$ & العدد & $\%$ & العدد الع ل المد & \\
\hline & - & - & 1,7 & 1 & $9 \wedge, \xi$ & r & \\
\hline & & & & أنص & & & (V) النصح لأحد الزملاء أو المعارف لحضور \\
\hline & $\%$ & العدد & $\%$ & العدد & $\%$ & 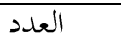 & \\
\hline & - & - & $7, \Gamma$ & $\varepsilon$ & $9 r, v$ & 7. & \\
\hline 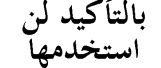 & تخدمها & ربما ل & ل بمها & ربما سو & 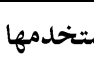 & 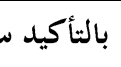 & الاتصالية الت تضمنهام البر نامجارف التدريح. والمهارات \\
\hline العدد & $\%$ & العدد & $\%$ & العدد & $\%$ & العدد & \\
\hline- & - & - & $1 \cdot, 9$ & $\mathrm{~V}$ & $\wedge 9,1$ & $\mathrm{OV}$ & \\
\hline & ل) & & & ملإ - la & & & 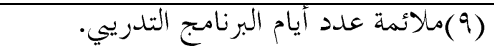 \\
\hline & $\%$ & 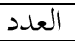 & $\%$ & العدد & $\%$ & العدد & \\
\hline & $r Y, \Lambda$ & YI & $07, \mu$ & T & $1 ., 9$ & $\mathrm{~V}$ & \\
\hline & ابب & & & جذا & & & (·) قدرة الختوى التدريي على جذب \\
\hline & $\%$ & 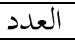 & $\%$ & 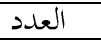 & $\%$ & 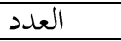 & انتباه و إثارة اهتمام المتدر بين. \\
\hline & - & - & r1,9 & $1 \varepsilon$ & $\vee \wedge, 1$ & 0. & \\
\hline & & & & ملائ & & & (1) (1) ملائمة عدد ساعات اليوم التدريي \\
\hline & $\%$ & 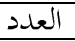 & $\%$ & العدد & $\%$ & العدد & \\
\hline & ri, 9 & $1 \varepsilon$ & $\varepsilon \wedge, \varepsilon$ & r & $r q, \vee$ & 19 & \\
\hline & لائم & & & ملادً & & & (Y) (I) ملائمة التسهيلات المتاحة (قاعات-- \\
\hline & $\%$ & العدد & $\%$ & العدد & $\%$ & 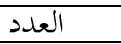 & إضاءة - وجبات - إقامة.... الخ). \\
\hline & $r o, \cdot$ & 17 & 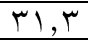 & $r$. & $\varepsilon \Gamma, V$ & rA & \\
\hline & & & 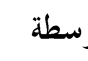 & 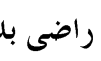 & كبيرة & راضى & التباس(1) درجة الرضا العام نهو البرنامج \\
\hline & $\%$ & 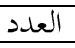 & $\%$ & العدد العد & $\%$ & العدد & \\
\hline & $r, 1$ & r & $1 \wedge, 1$ & Ir & $\vee \wedge, 1$ & $\circ$. & \\
\hline
\end{tabular}




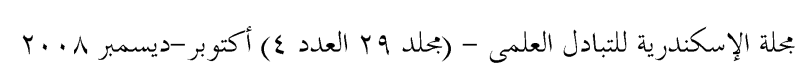

\begin{tabular}{|c|c|c|}
\hline ***0\% & التكر ارث & الآراء \\
\hline$\uparrow \wedge, \wedge$ & $\varepsilon \varepsilon$ & زيادة عدد أيام البرنامج التدريى \\
\hline ro,. & 17 & مر اعاة مدى مناسبة قاعة التدريب لنوعيته \\
\hline r & 10 & قلة عدد ساعات العمل في اليوم الواحد \\
\hline$I V, Y$ & 11 & زيادة عدد الجلسات العملية \\
\hline $1 \varepsilon, 1$ & 9 & زيادة المشاركة من قبل المتدربين \\
\hline $1 \cdot, 9$ & v & تقليل عدد المتدربين في كل دورة تدريبية \\
\hline $9, \varepsilon$ & 7 & المتابعة للمتدربين بعد أنتهاء البرنامج التدريى \\
\hline $7, r$ & $\varepsilon$ & استخدام المعينات التدريبية الحديثة \\
\hline$\varepsilon, v$ & r & زيادة عدد المدربين للبرنامج التدريى الواحد \\
\hline \multirow[t]{2}{*}{$\varepsilon, v$} & r & عدم اقتصار التدريب على الفترات الصباحية \\
\hline & & 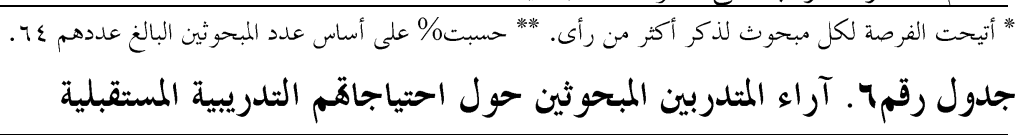 \\
\hline ***\% $\%$ & التكرار" & الاحتياجات التدريبية \\
\hline Or, 1 & $r \varepsilon$ & مهارات الاتصال الفعال \\
\hline$r q, V$ & 19 & اختيار واستخدام المعنيات التدر يبية \\
\hline$I V, r$ & 11 & الإعداد التفصيلى للمحتوى التدريى \\
\hline Kr,o & $\wedge$ & حل المشكلات و اتخاذ القرارات \\
\hline १, ₹ & 7 & تحديد وصياغة الأهداف التدريبية \\
\hline$\vee, \wedge$ & 。 & كيفية إدارة الاجتماعات ل"'." \\
\hline$\vee, \wedge$ & ○ & مشاكل التصدير وعمل الموازنات التصديرية \\
\hline$\vee, \wedge$ & ○ & الزراعة الآمنة \\
\hline$\varepsilon, v$ & r & كيفية تقييم البرنامج التدريى \\
\hline$\varepsilon, v$ & r & تعلم اللغة الإنجليزية \\
\hline$r, 1$ & r & الدعوة و كسَب الرأي \\
\hline$r, 1$ & r & التخطيط الاستراتيجى \\
\hline
\end{tabular}

* أتيحت الفرصة لكل مبحوث لذكر أكثر من احتياج. ** حسبت \% على أساس عدد المبحوثين البالغ عددهم ع؟.

ساعات العمل في اليوم التدريي الواحد. وتتفق تلك النتائج مع ما

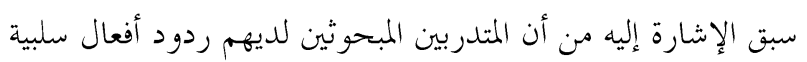

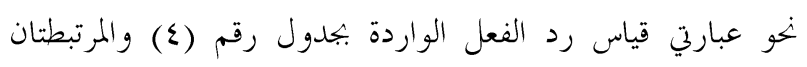

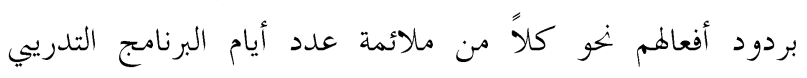

$$
\text { وملائمة عدد ساعات اليوم التدريي الواحد. }
$$

(ب) آراء المتدربين المبحوثين حول احتياجاقم التدريبية المستقبلية: تعكس البيانات الواردة بجدول رقم (7) عدد من الاحتياجات

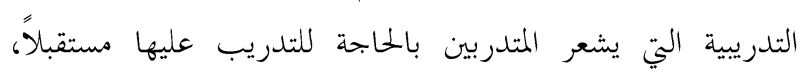

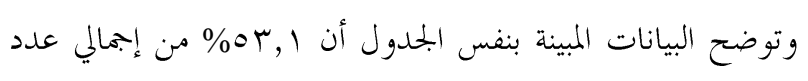

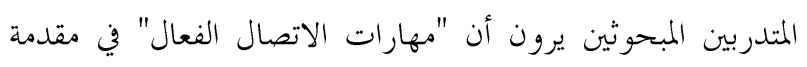

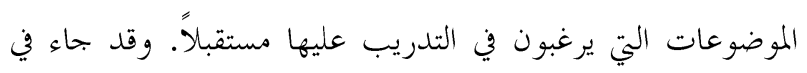

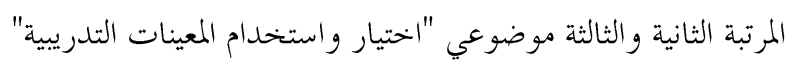

وبسؤال المتدربين المبحوثين عن درجة رضاهم العامة عن البرنامج

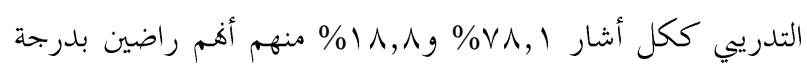

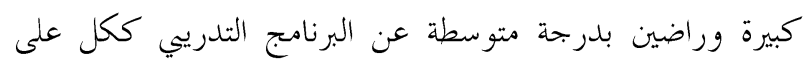

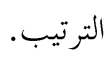
هي (T) آراء المتدربين المبحوثين حول كيفية تحسين البرنامج الثدريبي محل الدراسة: اهتمت الدراسة الحالية بالنظر إلى آراء المتدربين

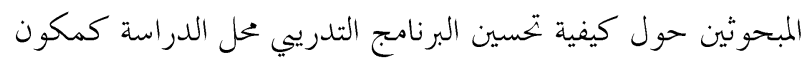

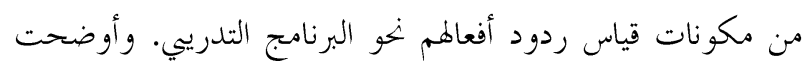
النتائج الواردة بجدول رقم (0) أن أكثر من ثلثي المبحوثين

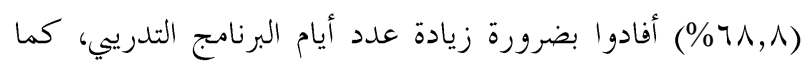

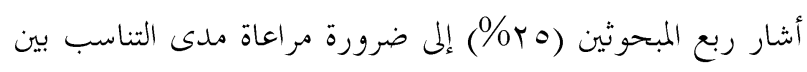

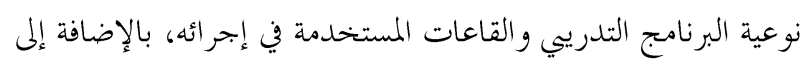

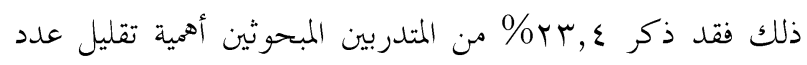


الاجتماعية بالبحيرة والاتحاد الإقليمي للجمعيات والمؤسسات

الخاصة.

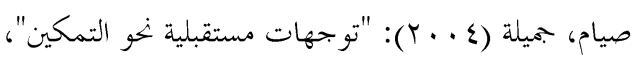

(OnLine) Available:

(http://www.home,birzeit.edu/cds/arabic/reserch/2004/p hdr060.html)

طاحون، عدلي علي، وخالد عبد الفتاح قنيبر (1997): "محددات

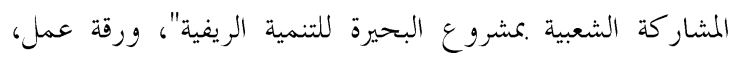

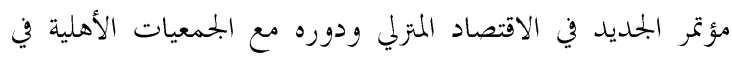

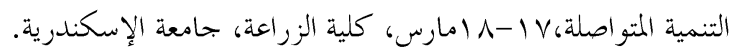

عبد المقصود، هججت (1 (9 1)): "الإرشاد الزراعي"، المنصورة: دار الوفاء

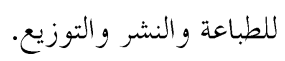

عثمان، ممد على(919 (19): "نحو طرائق وأساليب واستراتيجيات

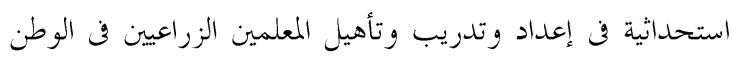

$$
\text { العربل"، مكتب اليونسكو الإقليمي للتربية في الدول العربية. }
$$

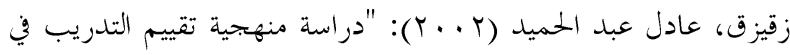

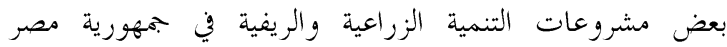

العربية"، رسالة دكتور اه، كلية الزراعة، جامعة الإسكندرية.

Confer, S. (1981). Training Volunteers. In Stanley M. and Associates, Preparing Educators of Adults. San Francisco: Jossey-Bass Publishers.

Douglah, M. (1998). Developing A Concept of Extension Program Evaluation. University of Wisconsin-Extension, Cooperative Extension, G3658-7 Program Development and Evaluation.

Hakimian, H. and Teshome, A. (1993). Trainers' Guide: Concept, Principles and Methods of Training: Rome, Food and Agriculture Organization of the United Nations.

Janhns, Irwin (1981). Training in Organizations. In Stanley M. Grabowski and Associates. Preparing Educators of Adults. San Francisco: Jossey- Bass Publishers.

Klatt, Bruce (1999). The Ultimate Training Workshop Handbook: A Comprehensive Guide to Leading Successful Workshops and Training Programs: McGraw.Hill Companies, Inc.

Kroehnert, Gary (2000). Basic Training for Trainers: A Handbook for New Trainers, 2nd Edition: McGraw. Hill Australia.

Lund, Richard E. (1987). A User's Guide to MSUSTAT Statistical Package. Bozeman, MT: Research and

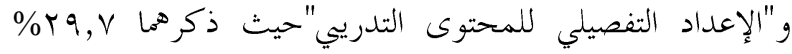

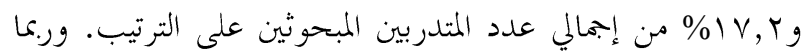
تشير تلك النتائج إلى إدراك المتدربين المبحوثين لأهم مواصفات المدرب الناجح والمتمثلة في مهارته على: الاتصال مع المتدربين واختيار واستخدام المعنيات التدريبية وإعداد الختوى التدريي. كما أن هناك عدد من الموضوعات لم يذكرها إلا عدد قليل من

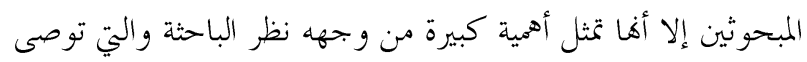

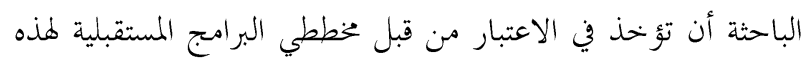

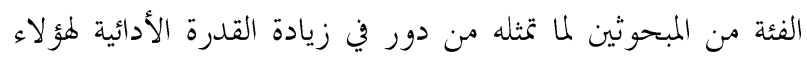

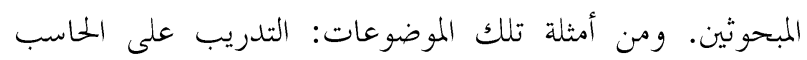

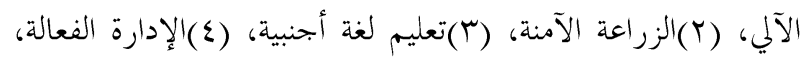

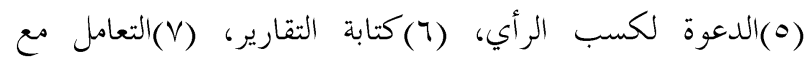

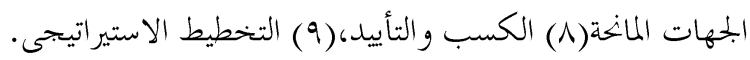

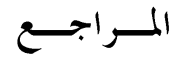

السيد، مصطفى كامل (1997) (العول "امل الخحددة لمشاركة النساء في أنشطة الجمعيات التطوعية في إحدى البختمعات الريفية الخحلية

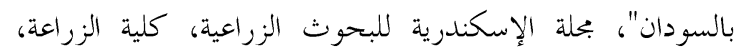
جامعة الإسكندرية، البحلد بع، العدد (1). العزبي، محمد إبراهيم (1999) (199 "دراسات في التنمية الريفية"، قسم البختمع الريفي، كلية الزراعة، جامعة الإسكندرية.

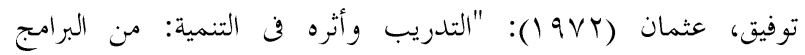

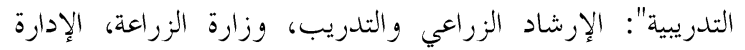
العامة للتدريب، الجزء الثامن.

جمعية تعليم الكبار الأمريكية- ترجمة عبد المنعم شوقى وسيد عبد الحميد

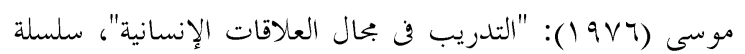

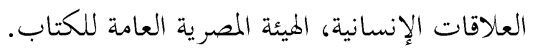

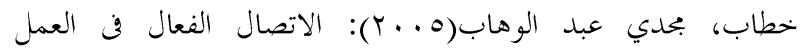

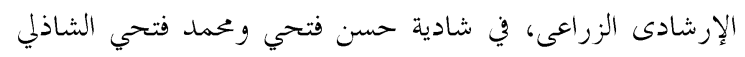

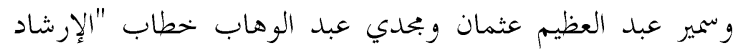
الزراعي"، S \& S Computer Center، الإسكندرية. شديد، محمد جمال (1997) (199): "مشاركة المواطنين ودور الهيئات الأهلية في تدعيم هذه المشاركة في محافظة البحيرة"، مديرية الشئون 


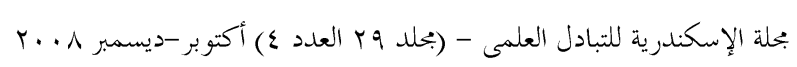

Development Institute, Inc., Montana State University.

Roling, N. and Engel, P. (1991). The Development of the Concept of Agricultural Knowledge Information Systems (AKIS): Implication for Extension. In William M. and Danial J. (eds.) Agricultural Extension Worldwide Institutional Evolution and Forces for change. London: Elsevier Science Publishers.
Saylor, J. and Associates (1981). Currculum Planning for Better Teachning and Learning. New York: Holt, Rinehart and Winston.

Taylor, E. and Renner, M. (2000). Collecting Evaluation Data: End-of- Session Questionnaires. University of Wisconsin- Extension, Cooperative Extension. G3658-11 Program Development and Evaluation.

Werther, Jrand and Davis, Keith (1980). Personnel Management and Human Resources. London: McGraw-Hill International Book Company. 


\title{
SUMMARY
}

\section{Educational Effects of an Extension Training Program on Training of Trainers for the Members of Farmer's Development Associations in Upper Egypt}

\author{
Hoda Mohamed Maher
}

The central purpose of this study was to identify the educational benefits of an extension training program in the field of training of trainers for the members of farmers and their families' development associations in upper Egypt. Two approaches were used in this study. First, the learning measurement approach was used to identify the degree of educational benefits the trainers gained, in terms of knowledge and skills, from the offered training program which was revealed by 45 educational items. Second, the reaction measurement approach was used to identify each of the following: (1) Trainees opinions related to the important dimensions of reaction measurement process of the studied training program. (2) Trainees opinions related to the future improvement of the training program. (3) Trainees opinions related to their training needs. Data were collected from 64 trainees participated in the studied program. Main statistical methods used for data analysis included: frequencies, percentages, means, and range. By comparing the knowledge and skill educational items before training with the knowledge and skill educational items after training, it was clear that the studied training program was very effective in increasing the trainees' knowledge in the field of training of trainers when compared with trainees' skills in the field of training of trainers. The results of this study should be regarded as a basis for designing and implementing similar programs in the future. 